\title{
МОДИФИЦИРОВАННЫЙ ЦИКЛОДЕКСТРИНОМ СОПОЛИМЕР ПОЛИ(2-ДЕОКСИ-2-МЕТАКРИЛАМИДО- $D$-ГЛЮКОЗЫ)*
}

1 Санкт-Петербургский государственный университет,

Российская Федерация, 199034, Санкт-Петербург, Университетская наб., 7-9

2 Институт высокомолекулярных соединений РАН, Российская Федерация, 199004, Санкт-Петербург, Большой пр. В. О., 31

Методами вискозиметрии и динамического рассеяния света (ДРС) исследованы молекулярные свойства новых синтетических биосовместимых сополимеров. Объектами изучения были сополимер 2-деокси-2-метакриламидо- $D$-глюкозы с акриловой кислотой (MAГ-АК) и его аналог, модифицированный бета-циклодекстрином. Определены характеристическая вязкость, молекулярная масса, коэффициент поступательной диффузии и гидродинамический размер молекул сополимеров в $0,2 \mathrm{M} \mathrm{NaCl}$. Изучены условия образования комплекса между сополимерами МАГ-АК, модифицированными бета-циклодекстрином и холестерином, и показано, что исследование таких интерполимерных комплексов методом ДРС требует особых условий. Библиогр. 7 назв. Ил. 3. Табл. 2.

Ключевые слова: поливинилсахариды, бета-циклодекстрин, холестерин, гидродинамические свойства.

\section{A. Slyusarenko ${ }^{1}$, M. L. Levit ${ }^{2}$, N.P. Yevlampieva ${ }^{1}$}

\section{POLY(2-DEOXY-2-METHACRYLAMIDO-D-GLUCOSE) COPOLYMER MODIFIED BY CYCLODEXTRIN}

1 St. Petersburg State University,

7-9, Universitetskaya nab., St. Petersburg, 199034, Russian Federation

2 Institute of Macromolecular Compounds of Russian Academy of Sciences,

31, Bolshoy pr. V. O., St. Petersburg, 199004, Russian Federation

The solution properties of novel synthetic biocompatible polymers have been investigated. Copolymers of 2-deoxy-2-methacrylamido- $D$-glucose with acrylic acid modified by $\beta$-cyclodextrin (MAG-AA- CD) or cholesterol (MAG-AA- Chol) were the objects of the study by the methods of viscometry, refractometry and dynamic light scattering in $0.2 \mathrm{M} \mathrm{NaCl}$. Such macromolecular parameters as translation diffusion coefficient $D$, hydrodynamic radius $R_{h}$, and intrinsic viscosity value $[\eta]$ were determined. Also there were analyzed the conditions for complex formation between $\mathrm{MAG}$ - AK - $\mathrm{CD}$ and $\mathrm{MAG}-\mathrm{AA}$ - Chol. After obtaining experimental data the results have shown that it demands specific condition of complex formation, suitable for the study of dynamic light scattering. Refs 7. Figs 3. Tables 2.

Keywords: polyvinylsaccharides, betha-cyclodextrin, cholesterol, hydrodynamic properties.

Введение. Биосовместимые синтетические полимеры широко применяются в современной фармакологии, и спектр их применения постоянно расширяется [1]. Такие полимеры используются и как фармакологические препараты, и как компоненты многих лекарственных форм и композиций. Поливинилсахариды, к которым относятся объекты исследования данной работы - производные поли (2-деокси-2-метакриламидо- $D$ глюкозы) (ПМАГ), - типичные представители класса биосовместимых синтетических полимеров.

* По материалам IV конференции «Современные проблемы молекулярной биофизики», посвящённой 50-летию специализации «Молекулярная биофизика» на физическом факультете и 105-летию со дня рождения профессора Э. В. Фрисман, 14-15 июня 2016 г., СПбГУ, Санкт-Петербург, Россия, URL: http://molbioph.niif.spbu.ru/conference.

(C) Санкт-Петербургский государственный университет, 2016 
Избыточный холестерин является причиной нарушения обмена веществ в организме человека. Его повышенная концентрация может приводить к возникновению сердечно-сосудистых и многих других заболеваний. Для регулирования уровня холестерина и удаления его избытков из организма можно использовать водорастворимые нетоксичные полимеры, содержащие связывающие холестерин лиганды [1]. В последнее время в ряде исследований было показано, что для активного связывания холестерина могут применяться биосовместимые полимеры с $\beta$-циклодекстрином в качестве боковых заместителей [2-4].

Циклодекстрины (ЦД) - это известная серия макроциклических олигосахаридов, которые получают разложением крахмала с помощью бактериальных ферментов [1]. цД способны связывать разные соединения за счёт нескольких типов взаимодействия, в числе которых могут быть названы ван-дер-ваальсовы силы, гидрофобные взаимодействия, электростатическое сродство, диполь-дипольные взаимодействия и образование водородных связей. Этому способствует большое количество ОН-групп, торообразная форма и наличие внутренней полости у молекул ЦД (рис. 1). $\beta$-Циклодекстрин ( $\beta$-ЦД), состоящий из 7 моноциклов $D$-глюкозы, наиболее известен среди других ЩД.

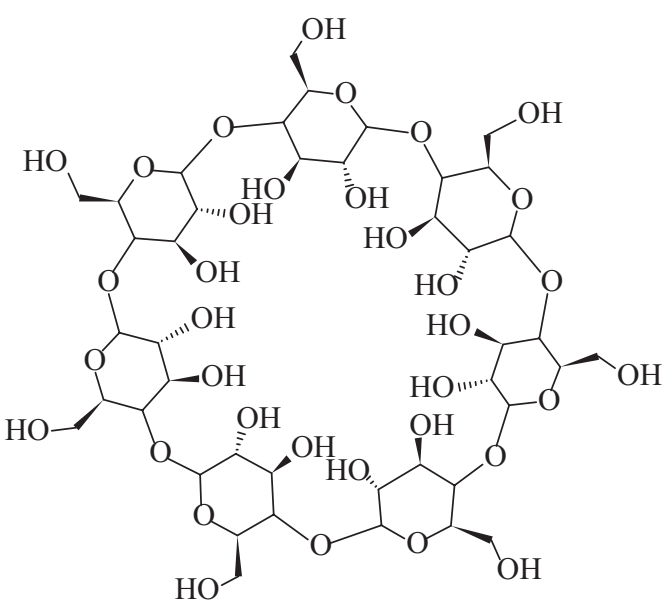

Рuc. 1. Химическая структура $\beta$-циклодекстрина

Сополимеры ПМАГ, модифицированные $\beta$-ЦД, исследованы пока недостаточно. Упомянутые выше работы [2-4] посвящены, в основном, синтезу. Полимеры, предназначенные для введения в организм, должны строго контролироваться по молекулярной массе и размерам макромолекул, поэтому необходимо детальное исследование их свойств в растворах. Задачей представляемой работы было изучение гидродинамических свойств исходного сополимера 2-деокси-2-метакриламидо- $D$-глюкозы (МАГ) с акриловой кислотой $(\mathrm{AK})$ (МАГ-АK) и его модифицированных $\beta$-ЩД и холестерином аналогов, а также проверка способности связывать холестерин сополимера, содержащего $\beta$-ЩД.

Экспериментальная часть. Исходный сополимер МАГ-АК (рис. 2) со средним мольным соотношением мономеров 86,5 : 13,5 мол. \% был получен методом свободнорадикальной сополимеризации мономеров в продутых аргоном запаянных ампулах, при температуре 313 K в течение 24 ч. Синтез проводили в растворе диметилформамида. Осаждали сополимер диэтиловым спиртом. Очистку от низкомолекулярных примесей осуществляли диализом против воды с помощью мембран. Выделенный сополимер сушили лиофильно. Мольный состав определяли методом ЯМР $\mathrm{C}^{13}$ в ИВС РАН. Полученный описанным способом сополимер МАГ-АК далее

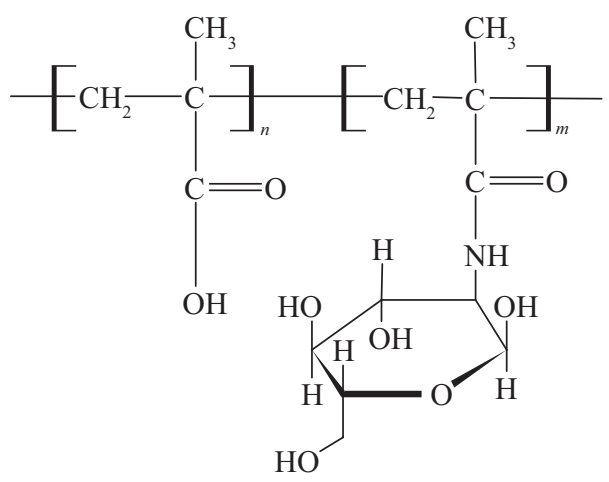

Рuc. 2. Химическая структура исходного сополимера МАГ-АК 
химически модифицировали $\beta$-ЦД или холестерином, присоединение которых к цепи сополимера осуществлялось за счёт взаимодействия с мономерными звеньями акриловой кислоты [2-4] (рис. 2).

Молекулярная масса $M_{w}$ сополимеров была определена ранее методом статического светорассеяния. Вискозиметрические измерения проведены с использованием микровискозиметра Lovis M2000 (Anton Paar), в конструкции которого для определения вязкости растворов применён метод Гепплера [5]. Характеристическую вязкость [ๆ] полимеров определяли:

$$
\frac{\eta_{\mathrm{sp}}}{c}=[\eta]+k^{\prime}[\eta]^{2} c+\ldots
$$

где $\eta-$ вязкость раствора; $\eta_{0}-$ вязкость растворителя; $\eta_{\mathrm{sp}}=\left(\eta_{0}-\eta\right) / \eta_{0}-$ удельная вязкость; $\eta_{\mathrm{sp}} / c-$ приведённая вязкость; $c$ - концентрация раствора; $k^{\prime}-$ константа Хаггинса [5].

Для измерения динамического рассеяния света (ДРС) была использована установка Photocor Complex (Москва, Россия) ресурсного центра СПбГУ «Центр диагностики функциональных материалов для медицины, фармакологии и наноэлектроники». Длина волны лазерного источника света составляла 654 нм, мощность - 25 мВт. Измерения проводили при углах рассеяния от 30 до $140^{\circ}$ и температуре $298 \mathrm{~K}$. Полученные данные обрабатывали с помощью программы DYNALS [6]. Гидродинамические радиусы $R_{h}$ макромолекул вычисляли, используя соотношение Стокса-Эйнштейна $R_{h}=k T /\left(6 \pi \eta_{0} D\right)$, где $k-$ постоянная Больцмана; $T$ - абсолютная температура; $\eta_{0}$ - вязкость растворителя, и определённые методом ДРС коэффициенты поступательной диффузии $D_{0}=\lim _{c \rightarrow 0} D$ (рис. 3) [7].

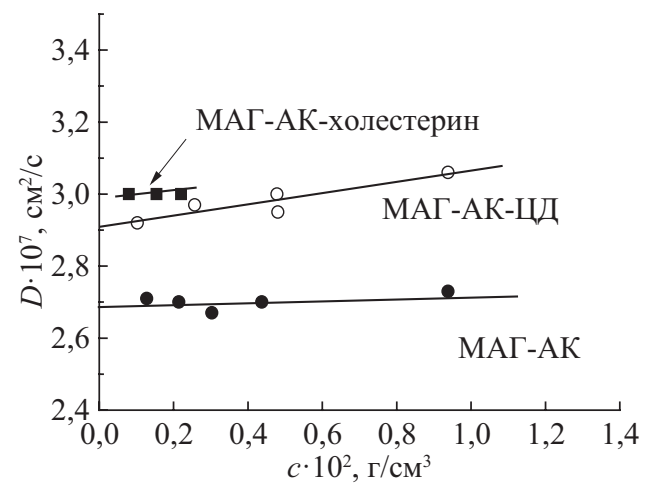

Puc. 3. Концентрационная зависимость коэффициентов диффузии $D$ молекул сополимеров в $0,2 \mathrm{M} \mathrm{NaCl}$

Обсуждение результатов. В табл. 1 приведены молекулярные характеристики исследованных образцов сополимеров и их состав. На одну молекулу МАГ-АК-ЦД приходилось $\approx 8$ боковых ЦД-заместителей и столько же холестериновых заместителей на одну молекулу МАГ-АК-Х. Несмотря на то что основные цепи у всех сополимеров одной и той же длины, они различаются гидродинамическими свойствами. Как следует из данных таблицы, присоединение объёмных боковых заместителей приводит к заметной компактизации МАГ-АК в одном и том же растворителе.

Судя по изменению вискозиметрической постоянной Хаггинса $k^{\prime}$, можно предположить, что использованный растворитель отличается термодинамическим качеством для каждого из исследованных сополимеров [5]. 
Гидродинамические характеристики сополимеров в $0,2 \mathrm{M} \mathrm{NaCl}$ при $298 \mathrm{~K}$

\begin{tabular}{c|c|c|c|c|c}
\hline $\begin{array}{c}\text { Образец } \\
\text { (соотношение компонентов, \%) }\end{array}$ & $\begin{array}{c}M_{w} \cdot 10^{3}, \\
\Gamma / \text { моль }\end{array}$ & {$[\eta], \mathrm{cm}^{3} / \Gamma$} & $k^{\prime}$ & $\begin{array}{c}D_{0} \cdot 10^{7}, \\
\mathrm{~cm}^{2} / \mathrm{c}\end{array}$ & $R_{h}, \mathrm{Hм}$ \\
\hline МАГ-АК $(86,5: 13,5)$ & $207 \pm 7$ & $20,0 \pm 0,6$ & $0,46 \pm 0,03$ & $2,7 \pm 0,1$ & $9,0 \pm 0,3$ \\
\hline МАГ-АК-ЦД $(86,5: 10,3: 3,2)$ & $230 \pm 10$ & $18,0 \pm 0,6$ & $0,40 \pm 0,03$ & $2,9 \pm 0,2$ & $8,4 \pm 0,3$ \\
\hline МАГ-АК-Х $(86,5: 12,1: 1,4)$ & $220 \pm 10$ & $10,5 \pm 0,8$ & $4,0 \pm 0,3$ & $3,0 \pm 0,7$ & $8 \pm 2$ \\
\hline
\end{tabular}

Образец МАГ-АК-Х являлся моделью холестеринсодержащих соединений в живых организмах. С использованием этого сополимера были проверены связывающие способности МАГ-АК-ЦД. Задача заключалась в определении условий комплексообразования МАГ-АК-ЦД и МАГ-АК-Х, позволяющих исследовать комплекс в растворе. Методом ДРС установлено, что при простом смешивании растворов МАГ-АК-ЩД и МАГ-АК-Х формируются агрегаты больших размеров, т. е. было подтверждено, что МАГ-АК-ЦД и МАГ-АК-Х взаимодействуют в совместном растворе. Из анализа первых измерений ДРС, полученных при прямом сливании растворов МАГ-АК-ЦД и МАГ-АК-Х равных концентраций, был сделан вывод о том, что комплексообразование происходит при любых соотношениях их объёмов. Необходимо было найти такую методику смешивания растворов компонентов, чтобы комплексооборазование можно было изучать методом ДРС в деталях. Такими оказались условия, если по каплям добавлять раствор МАГ-АК-ЩД концентрации $0,5 \cdot 10^{-2}$ г $/ \mathrm{cm}^{3}$ в раствор МАГ-АК-Х при постоянном перемешивании. С использованием более высоких концентраций МАГ-АК-ЦД формировались только крупные полимерные частицы. Спектры времени релаксации частиц регистрировали после взаимодействия МАГ-АК-ЦД с МАГ-АК-Х в совместном растворе в течение 1 ч.

Таблица 2

Коэффициенты диффузии $D_{0}$ и гидродинамический радиус $R_{h}$ частиц в совместных растворах МАГ-АК-ЦД/МАГ-АK-Х в 0,2M NaCl при $298 \mathrm{~K}$

\begin{tabular}{c|c|c|c}
\hline Комплекс & $($ МАГ-АК-Х) $:($ МАГ-АК-ЦД $)$ & $D_{0} \cdot 10^{7}, \mathrm{~cm}^{2} / \mathrm{c}$ & $R_{h}$, нм \\
\hline 1 & $1: 1$ & 0,09 & 269 \\
\hline \multirow{2}{*}{2} & \multirow{2}{*}{$1,5: 1$} & 1 -я мода $2,9 \pm 0,4$ & $8 \pm 1$ \\
& & 2 -я мода $0,75 \pm 0,08$ & $32 \pm 3$ \\
& \multirow{2}{*}{$2: 1$} & 3 -я мода $0,10 \pm 0,02$ & $240 \pm 50$ \\
\hline \multirow{2}{*}{3} & & 1 -я мода $3,0 \pm 0,3$ & $8,1 \pm 0,8$ \\
& \multicolumn{2}{|c}{-я мода $0,70 \pm 0,07$} & $35 \pm 4$ \\
\hline
\end{tabular}

В табл. 2 показан результат взаимодействия сополимеров, полученный при вариации смешиваемых объёмов растворов концентрации $0,5 \cdot 10^{-2} \mathrm{r} / \mathrm{cm}^{3}$. Первая мода соответствует размерам исходных сополимеров (см. табл. 1), т. е. в растворе присутствуют не вступившие в комплекс молекулы исходных сополимеров. Наибольший интерес представляют собой частицы с размерами порядка 30 нм, которые всегда присутствовали в растворах комплексов. Их состав должен стать предметом дальнейшего анализа.

Заключение. В работе определены и сопоставлены гидродинамические характеристики $D_{0},[\eta]$ и $R_{h}$ сополимера MAK-AK состава $86,5: 13,5$ мол. \% и его производных, модифицированных $\beta$-циклодекстрином или холестерином. Установлено, что в $0,2 \mathrm{M} \mathrm{NaCl}$ модифицированные сополимеры имеют более компактные размеры в сравнении с исходным MAK-AK. Получены сведения об условиях комплексообразования 
сополимера МАГ-АК-ЩД (86,5 : 10,3 : 3,2) с холестеринсодержащим соединением. Разработана методика смешения растворов модифицированных сополимеров МАГ-АК, позволяющая изучать их взаимодействие в водных растворах.

\section{Литература}

1. Полимеры в биологии и медицине / под ред. М. Дженкинса. М.: Научный мир, 2011. 256 с.

2. Левит М. Л., Назарова О. В., Мойсеюк И. В., Добродумов А. В. и др. Водорастворимые полимерные производные $\beta$-циклодекстрина // Высокомол. соед. Сер. А. 2012. Т. 54, № 1. С. 112-120.

3. Киппер А. И., Левит М. Л., Назарова О. В., Панарин Е. Ф. Комплексообразование холестеринсодержащих полимеров в водных растворах // Биофизика. 2013. Т. 58, № 6. С. 809-811.

4. Левит М. Л., Назарова О. В., Некрасова Т. Н., Добродумов А. В. и др. Водорастворимые полимерные производные холестерина // Высокомол. соед. Сер. Б. 2010. Т. 52, № 12. С. 648-655.

5. Хохлов А. Р., Кучанов С. И. Лекции по физической химии полимеров. М.: Мир, 2000. 190 с.

6. Dynals software. URL: http://www.photocor.ru/dynals (дата обращения: 12.01.2017).

7. Berne B. J., Pecora R. Dynamic light scattering. New York: Courier Dover Publications, 2000. 377 p.

\section{References}

1. Biomedical polymers. Ed. by M. Jenkins. Cambridge, Woodhead Publ., Ltd., 2007. 236 p. [Russ. ed.: Polimery v biologii i meditsine. Pod. red. M. Dzhenkinsa. Moscow, Nauchnyi mir Publ., 2011. 256 p.]

2. Levit M. L., Nazarova O.V., Moiseiuk I. V., Dobrodumov A. V. et al. Vodorastvorimye polimernye proizvodnye $\beta$-tsiklodekstrina [Water-soluble polymeric derivatives $\beta$-cyclodextrin]. Vysokomol. soed. Ser. A [Macromolec. Compounds (A)], 2012, vol. 54, no. 1, pp. 112-120. (In Russian)

3. Kippep A. I., Levit M. L., Nazapova O. V., Panapin E. F. Kompleksoobrazovanie kholesterinsoderzhashchikh polimerov $\mathrm{v}$ vodnykh rastvorakh [Complex formation of cholesterol-containing polymers in water solutions]. Biofizika [Biophysics], 2013, vol. 58, no. 6, pp. 809-811. (In Russian)

4. Levit M. L., Nazarova O. V., Nekrasova T. N., Dobrodumov A. V. et al. Vodorastvorimye polimernye proizvodnye kholesterina [Water-Soluble polymeric derivatives of cholesterol]. Vysokomol. soed. Ser. B [Macromolec. Compounds (B)], 2010, vol. 52, no. 12, pp. 648-655. (In Russian)

5. Khokhlov A. R., Kuchanov S. I. Lektsii po fizicheskoi khimii polimerov [Lectures on physical chemistry of polymers]. Moscow, Mir Publ., 2000. 190 p. (In Russian)

6. Dynals software. Available at: http://www.photocor.ru/dynals (accessed 12.01.2017).

7. Berne B. J., Pecora R. Dynamic light scattering. New York, Courier Dover Publications, 2000. 377 p.

Статья поступила в редакцию 30 июня 2016 г.

Контактная ин форм ация

Слюсаренко Мария Александровна - студентка; e-mail: st011436@student.spbu.ru

Левит Мария Леонидовна - кандидат химических наук; e-mail: m.levit@hq.macro.ru

Евлампиева Наталья Петровна - кандидат физико-математических наук, доцент;

e-mail: n.yevlampieva@spbu.ru

Slyusarenko M. A. — student; e-mail: st011436@student.spbu.ru

Levit M. L. — PhD; e-mail: m.levit@hq.macro.ru

Yevlampieva N. P. — PhD, Associate Professor; e-mail: n.yevlampieva@spbu.ru 